\title{
Selenium's Utility in Mercury Toxicity: A Mini-Review
}

\author{
Roswell Timmerman, Stanley T. Omaye \\ Department of Nutrition and the Environmental Sciences and Health Graduate Program, University of Nevada, Reno, USA \\ Email: omaye@unr.ed, roswellt@nevada.unr.edu
}

How to cite this paper: Timmerman, R. and Omaye, S.T. (2021) Selenium's Utility in Mercury Toxicity: A Mini-Review. Food and Nutrition Sciences, 12, 124-137. https://doi.org/10.4236/fns.2021.122011

Received: January 13, 2021

Accepted: February 15, 2021

Published: February 18, 2021

Copyright $\odot 2021$ by author(s) and Scientific Research Publishing Inc. This work is licensed under the Creative Commons Attribution International License (CC BY 4.0).

http://creativecommons.org/licenses/by/4.0/

\begin{abstract}
Purpose: This review of the literature intends to provide readers an understanding of the prophylactic and antidotal usefulness of selenium (Se) for mercury $(\mathrm{Hg})$ toxicity. We will provide an explanation of $\mathrm{Hg}$ and Se interactions for potential remediation options to contaminated ecosystems. Design/methodology/approach: In this mini-review, we discuss mechanistic aspects between $\mathrm{Hg}$ and $\mathrm{Se}$, the implication for health outcomes, and its usefulness in the ecological recovery of $\mathrm{Hg}$ contaminated areas. Findings: Mercury has a strong affinity for Se, resulting in Se-dependent enzymes and proteins' deactivation with devastating consequences to the host. It is likely that Hg's toxicity results in Se deficiency. Selenium compounds can have prophylactic or antidotal effects to prevent or reverse the adverse toxicity action of $\mathrm{Hg}$ exposure. Current research indicates that the chemical interactions between $\mathrm{Hg}$ and Se are unique. The $\mathrm{Hg}$ capturing capacity of Se is a million times higher than sulfur compounds and results in inactive complexes. Practical implications: Future work can target engineering methods for technologies that can reduce the toxicity of $\mathrm{Hg}$ in the environment. Originality/value: The unique interactions between the elements are that $\mathrm{Hg}$ can compromise Se dependent enzymes; however, pharmacologic doses of Se can prevent or modulate the toxic effects of Hg. Paper type: Literature review.
\end{abstract}

\section{Keywords}

Mercury, Selenium, Toxicity, Selenoproteins, Human Health, Oxidative Stress

\section{Introduction}

\subsection{Mercury}

Environmental mercury $(\mathrm{Hg})$ has the reputation of being a poison, and exposure to this element or derivatives of $\mathrm{Hg}$ either by ingestion or inhalation has been 
documented to result in adverse health effects. Both natural and anthropogenic sources result in $\mathrm{Hg}$ emissions with adverse environmental and human health issues. Human activities have increased $\mathrm{Hg}$ concentrations in the Earth's atmosphere by three-fold since the 1800s [1] [2] [3]. Once Hg enters the environment, it can be transformed by microbial organisms to a more bioavailable form, methyl $\mathrm{Hg}\left(\mathrm{CH}_{3} \mathrm{Hg}\right)$ [4], which is more readily absorbed by organisms and bioaccumulates. A buildup of $\mathrm{Hg}$ in food, such as; fish, can become health issues for larger animals and humans.

\subsection{Selenium}

Selenium (Se) at high concentrations can be a poison, too [5] [6] [7]; however, it is essential for life at low levels. In areas where Se is found in the soil, plants can absorb large concentrations, and animals that feed on such plants can result in Se toxicities. Acute Se toxicity caused by ingestion of Se leads to gastrointestinal and neurological disturbances, myocardial infarction, renal failure, acute respiratory, and distress syndrome. Since the 1970's we have known that Se is a cofactor for enzymes, which detoxify hydroperoxides and as a trace element required for the health of animals and humans [8]. There are interactions between mercury and selenium. These interactions are highlighted by the inhibition of mercury's toxic effects via selenium as well as mercury inducing its adverse health effects by disabling and inhibiting selenium dependent enzymes and proteins [8] [9] [10] [11]. It is the purpose of this review to summarize this information regarding Se and $\mathrm{Hg}$ interactions, giving particular emphasis on how scientists and regulatory agencies can utilize such information on dealing with ecological and human health exposure to Hg.

\section{Health Concerns for $\mathrm{Hg}$ and $\mathrm{Se}$}

\subsection{Mercury Toxicity}

Exposure to $\mathrm{Hg}$ has been linked to many pathological conditions and is recently associated with various disorders. This is disconcerting since $\mathrm{Hg}$ is pervasive in our environment and different consumer products ranging from dental amalgam, seafood, vaccines, and energy-saving light bulbs. Within our exposure to $\mathrm{Hg}$, there are different chemical forms $\mathrm{Hg}$, including elemental $\mathrm{Hg}$ (metallic, $\mathrm{Hg}^{\circ}$ ), inorganic, and organic $\mathrm{Hg}$ [12]. Elemental $\mathrm{Hg}$ can be found in thermostats, thermometers, dental amalgams, and has been added to latex paint, and under some situations, enters the atmosphere in a vaporized state [12] [13] [14]. Mercury $\left(\mathrm{Hg}^{\circ}\right)$ can penetrate across the blood-brain barrier where it can be oxidized to ionic $\mathrm{Hg}^{2+}$ intracellularly [12] [13] [14] and likely retained in the brain cells for years [15] [16] [17]. Inorganic $\mathrm{Hg}$ or $\mathrm{Hg}$ salts have been found as the formulations of cosmetic products, laxatives, teething powders, antiseptics, and diuretics. Organic $\mathrm{Hg}$ is considered as the greatest menacing form and the common form of $\mathrm{Hg}$ exposure, e.g., $\mathrm{CH}_{3} \mathrm{Hg}$ [4]. Organic $\mathrm{Hg}$ has been found in various sources, e.g., fish, poultry, insecticides, fungicides, pesticides, and was 
commonly found in thimerosal-containing vaccines.

\subsection{Selenium Toxicity}

Selenium salts are toxic in massive amounts [5] [6]. Selenium requirements in plants vary by species, with some plants requiring relatively large quantities and others requiring none. Excess Se excretes in the breath as a volatile compound [5]. Selenosis (chronic selenium toxicity) is commonly associated with nail structure changes, loss of nails and hair. Upon further ingestion, lesions of the skin and the nervous system occur [6]. Other symptoms include; nausea, weakness, and diarrhea. Selenium salts are toxic in large amounts, but trace amounts are required for cellular function in many organisms, including all animals. In the case of an excessively high dose, excess excretes in the form of urine. Also, high consumption of Se results in high blood pressure and cancers such as melanoma, oropharyngeal, urinary, and lymphoid cancer [7].

\subsection{Selenium Essentiality}

Schwarz and Foltz [18] are accredited for the discovery of the essentiality of Se. They showed that dietary Se traces prevented liver necrosis in laboratory rats fed a diet deficient in vitamin $\mathrm{E}$ and sulfur amino acid. Subsequently, several investigators demonstrated that $\mathrm{Se}$ is a nutritionally essential element for various animal species and resulted in the widespread use of Se supplementation in animal feeds [19] [20]. Selenium was shown to be unconditionally essential for rats and chickens adequate in vitamin E in 1969 [20] and that the type of disease was found to be species dependent. Rats developed liver necrosis, while mice developed multiple necrotic degenerations of skeletal muscle, heart, kidney, liver, and pancreas. Reproductive failure occurs in males of both rodent species. Swine developed a cardiac condition, lambs developed muscular dystrophy, and turkeys developed a gizzard myopathy. Cattle develop a myopathy affecting skeletal and heart muscle. The minimum dietary Se requirements useful in preventing deficiency diseases in species were extraordinarily consistent across species, illustrating that common molecular regulatory mechanisms are shared among species. Most Americans meet the daily requirement for Se in adults ( $55 \mu \mathrm{g} /$ day); however, specific populations in Europe, Asia, and parts of Africa have intakes much less than $55 \mu \mathrm{g} /$ day, and Se deficiency is related to disease conditions. In parts of China, deficient intakes $(<25 \mu \mathrm{g} / \mathrm{da}$ ) may contribute to a type of juvenile cardiomyopathy (Keshan disease) that is avertible by Se supplementation [21]. In 1973 investigators at the University of Wisconsin illustrated that the enzyme glutathione peroxidase was a selenoprotein [22], confirmed by several groups after that [23] [24] [25] [26].

The amount of Se required to prevent deficiencies ranges from $15-70 \mu \mathrm{g} / \mathrm{day}$. The current recommended dietary daily allowance for Se is about $55 \mu \mathrm{g} /$ day for healthy adults [27]. Selenomethionine and selenocysteine are the selenium analogs of methionine and cysteine, respectively. Many plants incorporate Se in place of sulfur as selenomethionine [28]. However, in higher animals, seleno- 
methionine cannot be synthesized from inorganic Se. In general, enzymes in the plant world or animals will not differentiate between selenomethionine or methionine. Dietary selenomethionine originating from plants and animals fed selenomethionine mixes with the methionine pool and is incorporated into protein needs, unrelated to selenium status [28].

However, selenocysteine can be converted within the animal into selenide, and selenide is the form of Se used to synthesize selenoproteins. Se can enter directly into regulated Se metabolism for incorporation into selenocysteine and selenoproteins in the inorganic Se form. In turn, Selenoproteins are incorporated into enzymes as main component parts of the enzymes, which facilitate lowering of activation energy for reactions in several metabolic pathways, including thyroid hormone metabolism, antioxidant enzyme systems, immune functions [28]. The inorganic forms of Se are more accessible to the body. In contrast, the organic forms need first to be broken down before Se can be utilized for selenoproteins in the body.

Overall there are two body pools illustrated in Figure 1: 1) for entry for dietary Se for animals; the unregulated (selenomethionine) dietary forms of Se including the low-molecular-weight and protein forms of Se and 2) the well-regulated selenocysteine inorganic selenium.

The significant difference between these pools is that selenocysteine pools are homeostatically regulated by Se status, and the selenomethionine pool is not. The selenomethionine pool changes and is proportional to selenomethionine's dietary intake because selenomethionine cannot be synthesized from $\mathrm{Se}$ in animals [28]. Therefore, the synthesis of proteins that contain methionine will not differentiate between selenomethionine or methionine. To animals, the Se in these selenomethionine proteins is unavailable until the protein turns over. The selenocysteine pool consists of the Se in selenoproteins and low-molecular-weight inorganic forms of Se [28]. Mammalian selenoproteins always contain Se as selenocysteine. This pool responds to the dietary status of Se and results in the synthesis

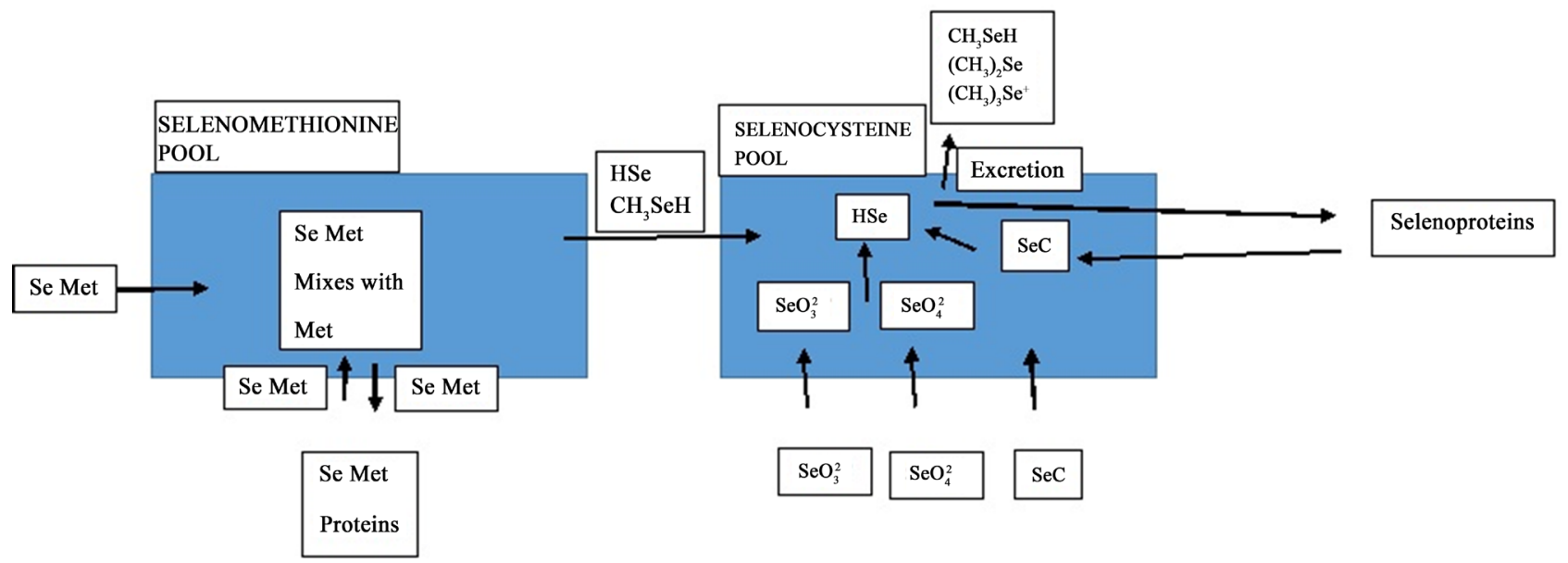

Figure 1. Selenium body pools: Selenomethionine (Se Met) pool; mixes readily with methionine (Met)and Selenocysteine (Sec); selenite $\left(\mathrm{SeO}_{3}^{2-}\right)$, selenite $\left(\mathrm{SeO}_{4}^{2-}\right)$, hydrogen selenide $(\mathrm{HSe})$, methyl selenide $\left(\mathrm{CH}_{3} \mathrm{SeH}\right)$, dimethyl selenide $\left(\left(\mathrm{CH}_{3}\right)_{2} \mathrm{Se}\right.$, and trimethyl selenide $\left(\left(\mathrm{CH}_{3}\right)_{3} \mathrm{Se}^{+}\right)$. 
of selenoprotein. The relationship between the two pools of Se is only in the direction of catabolism of selenomethionine to release selenide by the transsulfuration pathway [29] or methyl selenol through the decarboxylase pathway resulting in low molecular weight species that become part of the selenocysteine pool. The presence of Se metabolites facilitates methylation. The methylation is carried out by enzymes such as methyltransferase. Because of the reaction, dimethyl selenide, monomethyl selenide and trimethyl selenide metabolites materialize in the bloodstream. To perform the methylation, methyltransferase uses the methyl donor S-adenosyl methionine. The continual donation of the methyl group from S-adenosyl methionine consumes the molecule by depriving it of its methyl groups, a primary constituent to its structure. S-adenosyl methionine is considered to be a universal methyl donor. It functions to facilitate the transformation of homocysteine back into methionine. After that, adding more methionine to the pool and changing the concentration of the available S-adenosylmethionine since methionine is a principal constituent of the S-adenosylmethionine molecule.

A novel metabolic pathway is invoked to convert dietary forms of Se into the selenocysteine moiety found in selenoproteins involving the selenocysteine pool. Selenate or selenite must be reduced using glutathione (selenoenzyme thioredoxin reductase may catalyze this reaction). The reduction can occur in intestinal cells, erythrocytes, or other tissues. Synthesis of selenocysteine occurs during protein synthesis and involves several unusual intermediates, and requires at least five gene products. Each selenoprotein mRNA must contain two specific mRNA elements plus a unique selenocysteine s insertion sequence (SECIS) element for Se to incorporate. As illustrated in Figure 2, selenocysteine's synthesis starts with selenide and the formation of selenophosphate, which is the activated form of Se used in the synthesis of selenoprotein. The reaction is catalyzed by selenophosphate synthetase using ATP. Intact selenocysteine or selenomethionine is not used for synthesis; instead, the amino acid serine provides the carbon skeleton for selenocysteine.

In all selenocysteine-containing organisms, the synthetic cycle of selenocysteine

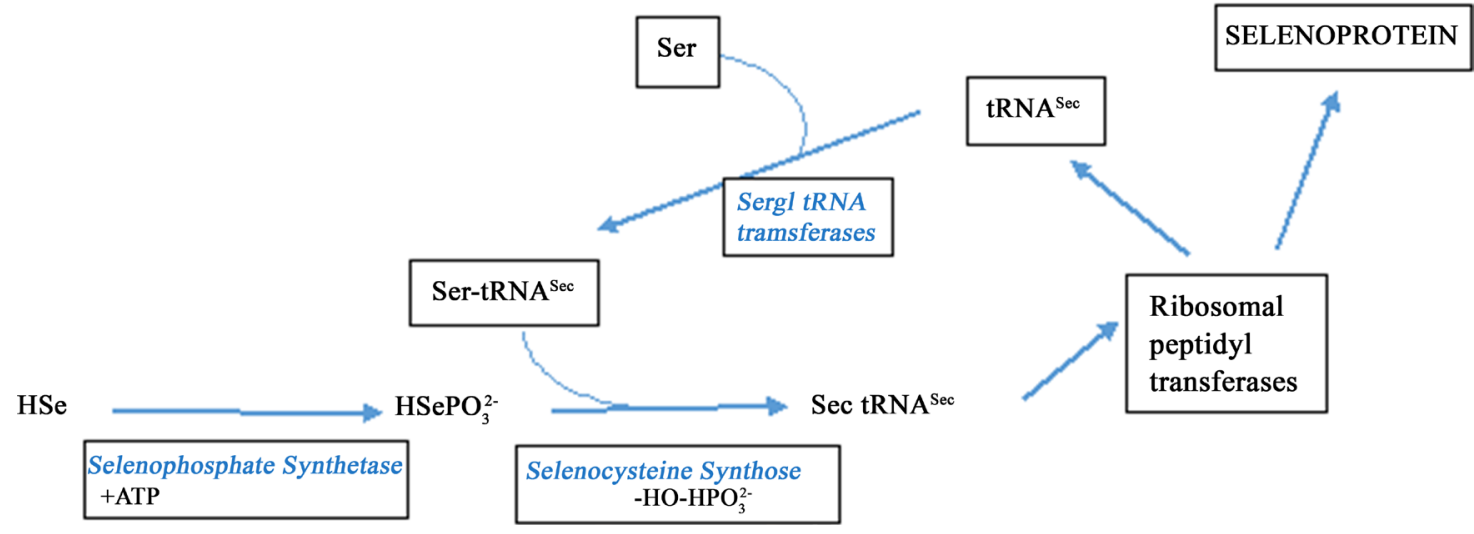

Figure 2. Selenocysteine synthesis. Serine (Ser), hydrogen selenide (HSe), Selenophosphate ( $\left.\mathrm{HSePO}_{3}^{2-}\right)$. 
begins with an essential "error:" seryl-tRNA synthetase (SerRS) "erroneously" charges selenocysteine tRNA (tRNA ${ }^{\mathrm{Sec}}$ ) with serine, thus yielding seryl-tRNA ${ }^{\mathrm{Sec}}$. The mischarged Ser-tRNA ${ }^{\text {Sec }}$ is not edited and is released into a solution to serve as an intermediate for the subsequent enzymatic reactions. The ability of SerRS to aminoacrylate two tRNAs with completely different anticodon sequences is unusual. It is even more perplexing that SerRS can act on both tRNA ${ }^{\text {Ser }}$ and tRNA $^{\text {Sec }}$ with significant efficiency, considering that the two tRNAs adopt completely distinct folds. Selenocysteine synthase replaces the serine $-\mathrm{OH}$ with $-\mathrm{SeH}$ from selenophosphate for form Sec-tRNA ${ }^{\text {Sec }}$. Selenocysteine is degraded by a Se-specific enzyme, selenocysteine lyase, which releases elemental Se. This Se is then reduced to selenide by glutathione or other thiols [28]. As illustrated in Figure 2, Sec is synthesized co-translationally from serine (Ser) and selenide (HSe) while esterified to tRNA $\mathrm{UCA}_{\mathrm{UCA}}^{\mathrm{SEC}}$ by the indicated enzymes.

Selenoenzymes are of vital importance in maintaining the balance of oxidation and reduction inside the cells. These enzymes contain very tightly bound forms of Se. They are metalloenzymes since they have trace metal elements in their molecular structures. The human genome encodes for about 25 of the (seleno-enzyme). A partial list of established selenoenzymes can be found tabulated by Combs [28]. They are the secondary after the metalloenzyme superoxide dismutase, which contains the metals copper and zinc. Selenium dependent (Se)-dependent enzymes (selenoenzymes) protect brain tissues against oxidative damage and perform other vital functions, but their synthesis requires a steady supply of Se [29]. The metalloenzymes of Se reduce the number of free radicals inside the cells. Free radical products can damage lipids and proteins inside cells and prevent them from performing their normal functions. Glutathione peroxidase is one of the selenoenzymes that offers the most protection from damaging free radicals. Glutathione peroxidase detoxifies hydroperoxides and works in concert with antioxidants that protect the animal's cells from damage due to the presence of free radicals [22] [23] [24] [25] [26].

\subsection{Novel Seleno Amino Acid, Selenocysteine}

The bulk of characterized selenoproteins are enzymes, most of which are involved in redox reactions. Their Sec residue is essential for the catalytic activity by taking part in the catalysis. That at least some selenoproteins are of major importance for mammalian life was unequivocally demonstrated by the mouse knockout of the selenocysteine-tRNA gene (necessary for Sec incorporation and thereby selenoprotein synthesis), which show early embryonic lethality [10]. Thus far, 25 human genes encode for selenoproteins, with several of these still having an unknown function. Selenoproteins have been found in all kingdoms of life, but individual organisms, like yeast or higher plants, lack selenoproteins. Remarkably, individual selenoproteins are generally different between different life domains, i.e., bacteria, archaea, and eukaryotes. Separate branches of organisms within these kingdoms of life have developed different selenoproteins [10] [30]. 


\section{Selenium Protective Effects against Mercury Toxicity}

Evidence demonstrating the prophylactic and antidotal usefulness of Se in $\mathrm{Hg}$ toxicity has been known for over 50 years, way before understanding the chemical mechanism of such interactions. The first recorded incident was when an injection of selenite into rats treated with mercury chloride prevented $\mathrm{Hg}$ toxicity [10] [30]. Subsequently, other reports became available, showing the positive tissue relationship between $\mathrm{Se}$ and $\mathrm{Hg}$ in protecting animals and humans from high $\mathrm{Hg}$ areas. An equimolar ratio of the two elements was first reported in livers of marine mammals [30], followed by the observation that Idrija Hg miners had the highest accumulating and retention of both elements. Regardless of the very high $\mathrm{Hg}$ concentrations, the morphologic damage was low when both factors were found in an equimolar ratio. Investigators have emphasized that there are two modes of interactions between Se and $\mathrm{Hg}$ [3] [11], Se co accumulation through the formation of nontoxic Hg-Se complexes and Se coexcretion Hg. It is essential in understanding Se protection against $\mathrm{Hg}$ toxicity to appreciate that critical target sites for $\mathrm{Hg}$ are Se-dependent enzymes and proteins [3] [9] [10] [17] [31].

\section{Chemistry between Se and $\mathrm{Hg}$ Interactions}

Early reports speculated that $\mathrm{Hg}$ becomes associated with lipid, particularly the $\mathrm{CH}_{3} \mathrm{Hg}$ form; however, in tissues, $\mathrm{Hg}$ can be bound to thiols or sulfhydryl with $\mathrm{K}_{\mathrm{a}}=10^{39}$ [9] [11] [32]. Although the interaction between thiol and sulfhydryl compounds and $\mathrm{Hg}$ was an attractive $\mathrm{Hg}$ toxicity mechanism, it was ironic that such compounds range $\sim 10,000$ times greater than the $1-25 \mu \mathrm{M}$ blood $\mathrm{Hg}$ level associated with $\mathrm{Hg}$ toxicity. However, the interaction between $\mathrm{Hg}$ and $\mathrm{Se}$ is estimated to be $\sim 1$ million-fold higher than for sulfur [9] [11] $\left(\mathrm{K}_{\mathrm{a}}=10^{45}\right)$. Thiol molecules likely function as vehicles that conduct $\mathrm{CH}_{3} \mathrm{Hg}$ onto selenoproteins or Se compounds. Such conclusions are consistent with the recent images generated using the GausView software program depicting a high binding affinity of $\mathrm{Hg}$ to Se [33] [34] [35] [36]. The much larger electron cloud of Se in comparison with $\mathrm{Hg}$ results in a robust molecular dipole. The action stables the molecule, which potentially contributes to the remarkably high binding affinities between these elements.

Se's ability to interact with $\mathrm{Hg}$ likely explains $\mathrm{Hg}$ toxicity to initiate Se deficiency and concurrent oxidative stress [33] [34]. In a recent report [35], it was shown that mercury selenide (HgSe) nanoparticles in the liver and brain of long-finned pilot whales are attached to Se-rich structures and possibly act as a nucleation point for the formation of large Se-Hg clusters, which can grow with age to over five $\mu \mathrm{m}$ in size. The detoxification mechanism is fully developed from the early period of the animals, with particulate $\mathrm{Hg}$ found in juvenile tissues. As a consequence of $\mathrm{CH}_{3} \mathrm{Hg}$ detoxification, Se-methionine, the selenium pool in the system, is depleted to maintain essential levels of Se-cysteine. These results suggest evidence of so far unreported depletion of the bioavailable Se 
pool, a plausible driving mechanism of demonstrated neurotoxic effects of $\mathrm{CH}_{3} \mathrm{Hg}$ in the organism affected by its high dietary intake. Also, it indicates the possible mode of action Se can play in the remediation of environmental issues involving $\mathrm{Hg}$ deposition and ways we might mitigate $\mathrm{Hg}$ contamination. The $\mathrm{Hg}$ capturing capacity of Se is a million times higher than the sulfur compounds. It is interesting that Se was used as filters and scrubber to capture $\mathrm{Hg}$ in metallurgical plants to combat toxic metal pollution [10] [36] [37] [38].

A recent study showed gram-negative bacteria performing the same function within the long-finned pilot whale within the brain and liver. That process was a formation of immobile SeHg compounds. The Se tied up the Hg preventing it from traveling anywhere outside of the cells in the brain and liver tissues. This article revealed that this process is also completed by the gram-negative bacteria $P$. fluorescens [39]. This single-celled organism performs the same function as the multicellular organs of the whale. The intracellular Se rendered the Hg immobile. This process readily occurs in the soil and sediment; however, it remains determined whether it happens in water. Within the water, dissolved $\mathrm{Hg}$ and Se levels are low, but this process likely occurs. These non-reactive and non-toxic complexes of $\mathrm{Hg}$ and Se provide hope for the use of Se as a remediation agent. The authors suggest a way of reducing the amounts of $\mathrm{Hg}$ in an ecosystem [39]. However, there is still much more research to be done since it only takes a small overdose of Se to endanger aquatic organisms. Therefore, carefully coordinated and controlled doses of optimally minimal amounts of Se would be necessary to reduce harm to aquatic ecosystems effectively. This requirement for immense caution represents the need for the development of new nanotechnologies. In the modern time, we have the technology to produce microscopic size particles of Se. This has led to the application of Se in nanoparticle (SeNP) forms. Out of the many applications of SeNPs reported in the literature, the use of varieties of nano-Se sorbents for capturing different forms of $\mathrm{Hg}$ was reported [40]. SeNPs capture sorbents are 300 times per unit mass more effective than other commercial sorbents. Such technology can be useful in the remediation and mitigation of $\mathrm{Hg}$ deposition in the environment or for new methods or detection or analysis [41] [42].

Current research has identified the possibility of synthesizing Se sulfide [40] that demonstrates the advancement recently made in the field of Se chemistry. Selenium can be delivered in such minute quantities and is a considerable step towards augmenting the legal aspects related to $\mathrm{Hg}$ remediation. The authors noted that scientists are discovering ways of synthesis using yeast for manufacturing chemical species [40]. Over the past year, the understanding related to the Se contained within yeast has rapidly advanced. A recent study describes the potential for yeast in Se supplementation in its primordial stages. Se-yeast's most abundant species was found to be SeMet, but there are over 60 types of Se-dependent yeast species reported [40]. The common method of characterizing and comparing Se-yeast was quantifying the total SeMet content, and the 
speciation analysis traditionally involves the determination of low-molecular-mass selenospecies [41].

\section{Ecosystem Remediation of $\mathrm{Hg}$}

The awareness of remediating areas that have become overburdened with $\mathrm{Hg}$ with Se is not new [42]. Several studies suggest this could be a realistic means of remediating decades of pollution that resulted from industrialization. Proper remediation will require very carefully coordinated doses of Se that are calibrated to be ecosystem specific, recognizing that there are no antidotes to Se overdose. Mercury became known as a problem starting in the 1970s. Soon after, it was discovered that $\mathrm{Hg}$ emitted from fossil fuel combustion could enter into aquatic ecosystems. A study utilized enclosures along with radioisotopes to measure the levels of $\mathrm{Hg}$ and Se in the sheltered Bay of Clay Lakee finding that Se and $\mathrm{Hg}$ become stored in the sediment [43]. In the following study [44] [45] illustrated how Se is beneficial as an antidote in water bodies that are more heavily contaminated, which explains the importance of the proper dosage being used and provides evidence for the effectiveness of the treatment.

A study in Sweden in 1991 showed that by the addition of Se selenite to eleven lakes, mercury levels were reduced [45] [46]. Adding the selenite in this way is known as the Boliden SRM-method. The fish studied were pike and perch. In their findings, the subgroup representing more heavily $\mathrm{Hg}$ contaminated fish shows a marked reduction in all individual perch samples of the different lakes. After one year of treatment, the average $\mathrm{Hg}$ concentration was reduced from 0.19 to $0.1 \mathrm{mg} \cdot \mathrm{kg}^{-1}, 48 \%$ [44]. Coupled with this reduction in the concentration of mercury in perch was an increase in Se's concentration. There was a rise in Se concentration from 0.29 to values between 5.3 and $7.0 \mathrm{mg} \cdot \mathrm{kg}^{-1}$.

The Se was added to the lakes after the lakes were already treated with lime, where calcium carbonate is added to raise the lake's $\mathrm{pH}$. The liming process with calcium carbonate reduces the $\mathrm{Hg}$ content of the perch, and it was shown to lower $\mathrm{Hg}$ levels by $30 \%$. Selenium can minimize $\mathrm{Hg}$ concentrations by $60 \%-$ $85 \%$. The Se gets added to the water by placing it into a skeleton that holds the mineral block. In the lakes in which there was poor circulation, the selenite under the ice during the winter caused a gradient to form around where the blocks are placed. The farther away from the blocks, the measuring is done, the lower the levels of Se. Such intervention is an effective way to add Se because it prevents Se's levels from becoming too high within the lake's food chain. Selenium was able to reduce the levels of $\mathrm{Hg}$ without the liming taking place beforehand. The findings show that the amount of Se and the addition's timing needs to be specific to the conditions of the lake that is being treated. The study indicates that Se is beneficial in treating levels with markedly higher levels of mercury contamination. While, in some circumstances, liming is an acceptable remediation method in the more severely contaminated lake, Se is required to cause a major change in the Hg concentrations [44]. There need to be studies done on 
other fish, and it can't be assumed that other species will react in the same way. Se compounds' capability to decrease the toxicity of $\mathrm{Hg}$ has been established in many species of mammals, birds, and fish investigated [45] [46]. Although there are skeptics [47] [48], proponents understand Se's potential to mitigate $\mathrm{Hg}$ contamination [10] [17] [38] [42] [44]. Knowledge of selenium's influence on mercury's effect in aquatic ecosystems and $\mathrm{Hg}$ exposure, bioaccumulation, and toxicity is considerable and directly requires increased attention.

\section{Future Research and Conclusion}

To perform accurate environmental and epidemiological $\mathrm{Hg}$ exposure risk assessments, we recommend that future studies will need to simultaneously assess the amounts and forms of Se that are also present. With further research, a full understanding of selenium's health and disease's role may become a reality. It could be the foundation for the treatment of $\mathrm{Hg}$ and perhaps other heavy metal intoxications and the remediation and mitigation of environmental issues. As noted, $\mathrm{Hg}$ is a global issue and technological methods to mitigate $\mathrm{Hg}$ are long overdue. Although beyond the scope of this review, many health disorders are potentially rooted in the alteration of Se status [28], which may be rooted in heavy metals' ability to inactivate Se dependent proteins. Finding ways to address such disorders through potential pharmaceutical or pharmacologic Se analog may be beneficial. Additional knowledge of $\mathrm{Hg}$ and Se's molecular interactions can lead to effective engineering technology for the environmental remediation of $\mathrm{Hg}$ and other heavy metal contaminations [49] [50].

\section{Acknowledgements}

Roswell Timmerman and Stanley T. Omaye wrote the paper. This review paper was written in partial fulfillment of the Master of Science degree requirements in Environmental Sciences at the University of Nevada, Reno.

\section{Conflicts of Interest}

The authors declare no conflicts of interest regarding the publication of this paper.

\section{References}

[1] Fitzgerald, W.J., Engstrom, D.R., Mason, R.P. and Nater, E.A. (1998) The Case for Atmospheric Hg Contamination in Remote Areas. Environmental Science \& Technology, 32, 1-7. https://doi.org/10.1021/es970284w

[2] Amos, H., Jacob, D.J., Streets, D.G. and Sunderland, E.M. (2013) Legacy Impacts of All-Time Anthropogenic Emissions on the Global Hg Cycle: Global Impacts of Legacy Hg. Global Biogeochemical Cycles, 27, 410-421.

https://doi.org/10.1002/gbc.20040

[3] Johanson, I.R. and Boyle, R.W. (1972) Geochemistry of Mercury and Origins of Natural Contamination in the Environment. CIM Trans, 75, 8-15.

[4] Ma, M., Du, H. and Wang, D. (2019) Mercury Methylation by Anaerobic Microor- 
ganisms: A Review. Critical Reviews in Environmental Science and Technology, 49, 1893-1936. https://doi.org/10.1080/10643389.2019.1594517

[5] Vinceti, M., Filippini, T., Cilloni, S., Argellini, A., Vergoni, A.V., Tsatsakis, A. and Ferrante, M. (2017) Health Risk Assessment of Environmental Selenium: Emerging Evidence and Challenges (Review). Molecular Medicine Reports, 15, 3323-3335. https://doi.org/10.3892/mmr.2017.6377

[6] Zwolak and Zaporowska, H. (2012) Selenium Interactions and Toxicity: A Review. Cell Biology and Toxicology, 28, 31-39. https://doi.org/10.1007/s10565-011-9203-9

[7] Hadrup, N. and Ravin-Haren, G. (2019) Acute Human Toxicity and Mortality after Selenium Ingestion: A Review. Journal of Trace Elements in Medicine and Biology, 58, Article ID: 126435. https://doi.org/10.1016/j.jtemb.2019.126435

[8] Weekley, C.M. and Harris, H.H. (2013) Which Form Is That? The Importance of Selenium Speciation and Metabolism in the Prevention and Treatment of Disease. Chemical Society Reviews, 42, 8870-8894. https://doi.org/10.1039/c3cs60272a

[9] Falnoga, I. and Tuske-Zuidaric, M. (2007) Selenium-Hg Interactions in Man and Animals. Biological Trace Element Research, 19, 212-220.

https://doi.org/10.1007/s12011-007-8009-3

[10] Ralston, N.V.C. and Raymond, L.J. (2010) Dietary Selenium's Protective Effects against methylHg Toxicity. Toxicology, 278, 112-123. https://doi.org/10.1016/j.tox.2010.06.004

[11] Ralston, N.V.C. and Raymond, L.J. (2018) Mercury's Neurotoxicity Is Characterized by Its Disruption of Selenium. Biochimica et Biophysica Acta, 1862, 2405-2415. https://doi.org/10.1016/j.bbagen.2018.05.009

[12] Bjorklund, G., Dadar, M., Mutter, J. and Aaseth, J. (2017) The Toxicology of Mercury: Current Research and Emerging Trends. Environmental Research, 159, 545-554. https://doi.org/10.1016/j.envres.2017.08.051

[13] Patrick, L. (2002) Mercury Toxicity and Antioxidants: Part I: Role of Glutathione and Alpha-Lipoic Acid in the Treatment of Mercury Toxicity. Alternative Medicine Review, 7, 456-471.

[14] Clarkson, T.W. and Magos, L. (2006) The Toxicology of Mercury and Its Chemical Compounds. Critical Reviews in Toxicology, 8, 609-662. https://doi.org/10.1080/10408440600845619

[15] Berlin, M., Zalups, R.K. and Fowler, B.A. (2007) Mercury. In: Nordberg, G., Fowler, R.A., Nordberg, M. and Friberg, L.T., Eds., Handbook on the Toxicology of Metals, 3rd Edition, Academic Press, Burlington, 675-729. https://doi.org/10.1016/B978-012369413-3/50088-4

[16] Crowe, W., Allsopp, P.J., Watson, G.E., Magee, P., Strain, J.J., Armstrong, D.J., Ball, E. and McSorley, E.M. (2016) Mercury as an Environmental Stimulus in the Development of Autoimmunity-A Systematic Review. Autoimmunity Reviews, 16, 72-80. https://doi.org/10.1016/j.autrev.2016.09.020

[17] Bjorklund, G., Aaseth, J., Ajsuvakova, O.P., Nikonorov, A.A., Skalny, A.V., Skalnaya, M.G. and Tinkov, A.A. (2017) Molecular Interaction between Mercury and Selenium in Neurotoxicity. Coordination Chemistry Reviews, 332, 30-37. https://doi.org/10.1016/j.ccr.2016.10.009

[18] Schwarz, K. and Foltz, C.M. (1957) Selenium as an Integral Part of Factor 3 against Dietary Necrotic Liver Degeneration. Journal of the American Chemical Society, 79, 3292-3293. https://doi.org/10.1021/ja01569a087

[19] Stadtman, T.C. (1996) Selenocysteine. Annual Review of Biochemistry, 65, 83-100. 
https://doi.org/10.1146/annurev.bi.65.070196.000503

[20] Institute of Medicine, Food and Nutrition Board (2000) Dietary Reference Intakes. National Academy Press, Washington DC.

[21] Zeng, H. (2009) Selenium as an Essential Micronutrient: Roles in Cell Cycle and Apoptosis. Molecules, 14, 1263-1278. https://doi.org/10.3390/molecules14031263

[22] Rotruck, J.T., Pope, A.L., Ganther, H.E., Swanson, A.B., Hafeman, D.G. and Hoekstra, W.G. (1973) Selenium: Biochemical Role as a Component of Glutathione Peroxidase. Science, 179, 588-590. https://doi.org/10.1126/science.179.4073.588

[23] Flohe, L., Gunzler, W.A. and Schock, H.H. (1973) Glutathione Peroxidase: A Selenoenzyme. F.E.B.S. Letters, 32, 132-134. https://doi.org/10.1016/0014-5793(73)80755-0

[24] Omaye, S.T. and Tappel, A.L. (1974) Effect of Dietary Selenium on Glutathione Peroxidase in the Check. The Journal of Nutrition, 104, 747-753.

https://doi.org/10.1093/jn/104.6.747

[25] Chow, C.K. and Tappel, A.L. (1974) Response of Glutathione Peroxidase to Dietary Selenium in Rats. The Journal of Nutrition, 104, 444-451.

https://doi.org/10.1093/jn/104.4.444

[26] Scott, M.L., Noguchi, T. and Combs, Jr., G.F. (1975) New Evidence Concerning Mechanisms of Action of Vitamin E and Selenium. Vitamins \& Hormones, 32, 429-444. https://doi.org/10.1016/S0083-6729(08)60021-7

[27] National Research Council (1989) Recommended Dietary Allowances (RDA) 10th Edition.

[28] Boyd, R. (2011) Selenium Stories. Nature Chemistry, 3, 570. https://doi.org/10.1038/nchem.1076

[29] Markand, S., Saul, A., Roon, P., Prasad, P., Martin, P., Rozen, R., Ganapathy, V. and Smith, S.B. (2015) Retinal Ganglion Cell Loss, and Mild Vasculopathy in Methylene Tetrahydrofolate Reductase (Mthfr)-Deficient Mice: A Model of Mild Hyperhomocysteinemia. Investigative Ophthalmology \& Visual Science, 56, 2684-2695. https://doi.org/10.1167/iovs.14-16190

[30] Combs, Jr., G.F. (2019) Selenium. In: Stipanuk, M.H. and Caudill, M.A., Eds., Biochemical, Physiological, and Molecular Aspects of Human Nutrition, Elsevier, Amsterdam, 882-900.

[31] Parizek, J. and Ostadalova, I. (1967) The Protective Effect of Small Amounts of Selenite in Sublimate Intoxication. Experientia, 23, 142-143.

https://doi.org/10.1007/BF02135970

[32] Dyrssen, D. and Wedburg, M. (1991) The Sulphur-Mercury (II) System in Natural Waters. Water Air \& Soil Pollution, 56, 507-519. https://doi.org/10.1007/BF00342295

[33] Branco, V., Caito, S., Farina, M., Rocha, J.B.T., Aschner, M. and Carvalho, C. (2017) Biomarkers of Mercury Toxicity: Past, Present and Future Trends. Journal of Toxicology and Environmental Health, Part B Critical Reviews, 20, 119-154. https://doi.org/10.1080/10937404.2017.1289834

[34] Branco, V. and Carvalho, C. (2019) The Thioredoxin System as a Target for Mercury Compounds. Biochimica et Biophysica Acta, 1863, Article ID: 129255. https://doi.org/10.1016/j.bbagen.2018.11.007

[35] Gajdosechova, Z., et al. (2016) In Vivo Formation of Natural HgSe Nanoparticles in the Liver and Brain of Pilot Whales. Scientific Reports, 6, Article No. 34361.

https://doi.org/10.1038/srep34361 
[36] Ralson, R. (2008) Nano-Selenium Captures Mercury. Nanotechnology, 3, 527-528. https://doi.org/10.1038/nnano.2008.251

[37] Wang, X., Zhang, D., Pan, X., Lee, D.J., Al-Misned, F.A., Mortuza, M.G. and Gadd, G.M. (2017) Aerobic and Anaerobic Biosynthesis of Nano-Selenium for Renedutuib of Mercury Contaminated Soil. Chemosphere, 170, 266-273. https://doi.org/10.1016/j.chemosphere.2016.12.020

[38] Chen, C., Yu, H., Zhao, J., Li, B., Qu, L., Liu, S., Zhang, P. and Chai, Z. (2006) The Roles of Serum Selenium and Selenoproteins on Mercury Toxicity in Environmental and Occupational Exposure. Environmental Health Perspectives, 14, 297. https://doi.org/10.1289/ehp.7861

[39] Yang, D.-Y., Chen, Y.-W. and Belzile, N. (2022) Evidences of Non-Reactive Mercury-Selenium Compounds Generated from Cultures of Pseudomonas fluorescens. Science of the Total Environment, 409, 1697-1703. https://doi.org/10.1016/j.scitotenv.2011.01.030

[40] Asghari-Paskiabi, F., Imani, M., Rafii-Tabar, H. and Razzaghi-Abyaneh, M. (2019) Physicochemical Properties, Antifungal Activity and Cytotoxicity of Selenium Sulfide Nanoparticles Green Synthesized by Saccharomyces cerevisiae. Biochemical and Biophysical Research Communications, 516, 1078-1084. https://doi.org/10.1016/j.bbrc.2019.07.007

[41] Constantinescu-Aruxandei, D., Frîncu, R.M., Capră, L. and Oancea, F. (2018) Selenium Analysis and Speciation in Dietary Supplements Based on Next-Generation Selenium Ingredients. Nutrients, 10, 1466. https://doi.org/10.3390/nu10101466

[42] Paulsson, K. and Lundbergh, K. (1989) The Selenium Method for Treatment of Lakes for Elevated Levels of Mercury in Fish. Science of the Total Environment, 87, 495-507. https://doi.org/10.1016/0048-9697(89)90256-8

[43] Turner, M. and Rudd, J. (2011) The English-Wabigoon River System: III. Selenium in Lake Enclosures: Its Geochemistry, Bioaccumulation, and Ability to Reduce Mercury Bioaccumulation. Canadian Journal of Fisheries and Aquatic Sciences, 40, 2228-2240. https://doi.org/10.1139/f83-259

[44] Paulsson, K. and Lundbergh, K. (1991) Treatment of Mercury Contaminated Fish by Selenium Addition. Water, Air, and Soil Pollution, 56, 833.

https://doi.org/10.1007/BF00342320

[45] Cuvin-Aralar, M.L. and Furness, R.W. (1991) Mercury and Selenium Interaction: A Review. Ecotoxicology and Environmental Safety, 21, 348-364. https://doi.org/10.1016/0147-6513(91)90074-Y

[46] Chapman, L. and Chan, H.M. (2000) The Influence of Nutrition on Methylmercury Intoxication. Environmental Health Perspectives, 108, 29-56. https://doi.org/10.2307/3454631

[47] Spiller, H.A. (2017) Rethinking Mercury: The Role of Selenium in the Pathophysiology of Mercury Toxicity. Clinical Toxicology, 56, 1-14. https://doi.org/10.1080/15563650.2017.1400555

[48] Gerson, J.R., Walters, D.M., Eagles-Smith, C.A., Bernhardt, E.S. and Brandt, J.E. (2020) Do Two Wrongs Make a Right? Persistent Uncertainties Regarding Environmental Selenium-Mercury Interactions. Environmental Science \& Technology, 54, 9228-9232. https://doi.org/10.1021/acs.est.0c01894

[49] Bozena, H., Hosnedlova, B., Kepinska, M., Skalickova, S., Fernandez, C., Ruttkay-Nedecky, B., Peng, Q., Baron, M., Melcova, M., Opatrilova, R., Zidkova, J., Bjørklund, G., Sochor, J. and Kizek, R. (2018) Nano-Selenium and Its Nanomedicine Applications: A Critical Review. International Journal of Nanomedicine, 13, 
2107-2118. https://doi.org/10.2147/IJN.S157541

[50] Wang, X., He, Z., Luo, H., Zhang, M., Zhang, D., Pan, X. and Gadd, G.M. (2018) Multiple Pathway Remediation of Mercury Contamination by a Versatile Selenium-Reducing Bacterial. Science of the Total Environment, 615, 615-623.

https://doi.org/10.1016/j.scitotenv.2017.09.336 